DESIDOC Bulletin of Information Technology, Vol. 27, No. 1, January 2007, pp. 69-76 (C) 2007, DESIDOC

\title{
Materials Science Research in India: A Scientometric Analysis
}

\author{
Rajpal Walke and S.M.Dhawan* \\ National Physical Laboratory, Dr K.S.Krishnan Marg, New Delhi-110 012 \\ E-mail: rajpalw@yahoo.com \\ *Library \& Information Consultant, 114 Dayanand Vihar, New Delhi-110 092 \\ E-mail:smdhawan@yahoo.com
}

\begin{abstract}
The paper analyses the growth and publications size of the Indian publications in materials science during 1993-2001. It also analyses various other features of publications output such as modes of communication, areas of research priority, research quality, nature of collaboration, and institutional productivity.
\end{abstract}

Keywords: Materials science, scientometric analysis, publications size

\section{INTRODUCTON}

Materials science has been defined variantly in the literature. According to the 1974 summary report of the Committee on the Survey of Materials Science and Engineering (COSMAT) of the United States National Academy of Sciences, the materials science has been defined as a multidisciplinary field concerned with the fundamental nature of materials and their applications, with the generations and application of knowledge relating to the composition, structure, and processing of materials to their properties and uses. This definition recognises three basic elements in the study of materials: structure, composition, and processing and properties. The Committee on Materials Science and Engineering of the National Research Council in its report, Materials science and engineering for the 1990s: Maintaining competitiveness in the age of Materials, provided another definition in which it added the fourth element-performance. According to this report, materials science is defined as the study of materials for controlling the four basic elements-properties; structure and composition; synthesis and processing; and performance, and understanding the strong interrelationships among them.

Materials science is synonymous with new and advanced materials. This new discipline has given rise to several new materials for weight reduction, optimal utilisation of energy, cost reduction, and greater efficiency. Their applications in computers, automobiles, 
communication equipment, structural products, etc. have radically altered the quality of our life in many ways; new appliances are lighter and efficient, automobiles and aeroplanes are using less fuel and going faster. Materials science is now offering advanced materials by exercising control over the structure of material even at nano, micro, and macro scales. Such materials are able to meet the stringent performance requirement imposed by most modern technologies such as supersonic aircraft, space vehicles, etc. Industries such as aerospace, automobiles, biomaterials, chemicals, electronics, energy, metals, communications are still looking for new improved and more economical materials and processes for meeting their critical needs. The economic and strategic impact of such developments on the society has been so profound that materials science has come to be recognised as an independent discipline in itself. The field continues to expand its knowledge base for breakthrough in structural materials, electronics materials, magnetic materials, photonic materials, super conducting materials, and biomaterials.

Even information technology owes a great deal of its tremendous developments to advances in materials science. It has led to the development of electronic and optical materials without which large-scale integration and fibre optic communication would not have become possible. Prof C N R Rao, one of the leading science policy makers of India considers the use of advanced technology materials as an index of development. Such has been its contribution to the society that materials science is now recognised as a subject of special importance.

India has a long tradition of working in the field of materials science. A number of institutions including academic, institutes of national importance, $R \& D$ sector, and industry are actively pursuing research on different aspects of materials science. For example, in the area of metals and alloys, several institutes such as Defence Metallurgical Research Laboratory (DMRL), Hyderabad; Indian Institute of Science (IISc), Bangalore; Indian Institute of Technology Bombay (IITB), Mumbai; Vikram Sarabhai Space Centre (VSSC),
Trivandrum; Bhabha Atomic Research Research Centre (BARC), Mumbai; MIDHANI, Hyderabad; National Metallurgical Laboratory (NML), Jamshedpur; and IDPL Chemicals Limited, Hyderabad are engaged in R\&D work. Similarly in area like polymers, some of the institute engaged in R\&D work are National Chemical Laboratory (NCL), Pune; Indian Institute of Technology Bombay (IITB), Mumbai and New Delhi; Central Leather Research Institute (CLRI), Chennai; etc. Most of the funding in materials science to various institutions in India comes from parents bodies as well as from extramural funding schemes of various government agencies/departments.

In the past, only few evaluation studies have been conducted in Indiæt rdhatsar, analysed research output from Indian institutions in seven categories of materials, viz., metals and alloys, aluminium, ceramics, composites, glass, polymers, and wood based on the database developed by INSDOC through funding from TIFAC during 1980-89. Mohan ${ }^{2}$, et al. studied the international collaborative papers of Indian scientists during 1995-99 as covered by Materials Science Citation Index.

\section{OBJECTIVES}

The objective of this paper is to study the $R \& D$ output from Indian institutions in the area of materials science during 19932001 with focus on growth and development, quality of research, institutional productivity and quality, collaborative profile, subject areas of priority, mode of communication, etc.

\section{METHODOLOGY AND SOURCES USED}

The results presented in the study are based on raw bibliographical publication data (along with their citations data) for the period 1993-2001 extracted and downloaded in February 2004 from the Science Citation Index-Expanded Version (SCIE) of the Thomson-ISI. The delineation of the broad and narrow subject areas in research publications was based on a set of journals assigned by the ThomsonISI to relevant subject categories. A number of absolute and relative indices were used 
for analysing performance of research in materials science in India.

\section{ANALYSIS AND RESULTS}

\subsection{Publications Size}

Publications data derived from the Web of Science revealed that India published 9545 papers in materials science during 19932001. At sub-field level their distribution shows wide variations. For example, multidisciplinary science accounts for the largest share (76.6 per cent) in the total country output in materials science, followed by ceramics (5.76 per cent), textile (4.27 per cent), coatings and films (4.06 per cent), materials characterisation and testing (3.03 per cent), biomaterials (1.48 per cent), and wood (0.68 per cent) (Table 1).

\subsection{Growth Rate}

The country has achieved an average growth rate of 7.09 per cent annually in the materials science research during 1993-2001, which marginally increased to 7.61 per cent during 1997-2001. It is evident that materials science research in the country is growing steadily. At sub-field level, average publications growth rate annually is much higher, ranging between 10.4 per cent and 242.5 per cent; the lowest being 10.4 per cent for ceramics and the highest being 242.5 per cent for textile (Table 2). The relatively higher growth rate of the country as seen at the sub-field levels in materials science compared to its 7.09 per cent growth rate as well as wide just 2.82 per cent rise. Comparing growth rate on cumulative data of three years, textile

Table 1. Publications output from India in materials science during 1993-2001

\begin{tabular}{|l|c|c|c|}
\hline Subject & $\begin{array}{c}\text { Publications } \\
\text { count }\end{array}$ & $\begin{array}{c}\text { Average } \\
\text { IF per } \\
\text { paper }\end{array}$ & $\begin{array}{c}\text { Per cent share } \\
\text { in total papers } \\
\text { in materials } \\
\text { science }\end{array}$ \\
\hline Biomaterials & 141 & 0.979 & 1.48 \\
\hline Ceramics & 550 & 0.897 & 5.76 \\
\hline Characterisation \& testing & 289 & 0.296 & 3.03 \\
\hline Coatings \& films & 388 & 1.034 & 4.06 \\
\hline Composites & 376 & 0.446 & 3.94 \\
\hline Multidisciplinary & 7328 & 0.909 & 76.77 \\
\hline Textile & 408 & 0.212 & 4.27 \\
\hline Wood & 65 & 0.333 & 0.68 \\
\hline Total & 9545 & 0.638 & 100.00 \\
\hline
\end{tabular}

Table 2. Publications growth in materials science for India during 1993-2001

\begin{tabular}{|l|c|c|c|c|c|c|c|c|c|}
\hline $\begin{array}{c}\text { Pub. } \\
\text { year }\end{array}$ & $\begin{array}{c}\text { Bio- } \\
\text { materials }\end{array}$ & Ceramics & $\begin{array}{c}\text { Characteri- } \\
\text { sation and } \\
\text { testing }\end{array}$ & $\begin{array}{c}\text { Coatings } \\
\text { and films }\end{array}$ & $\begin{array}{c}\text { Compo- } \\
\text { sites }\end{array}$ & $\begin{array}{c}\text { Multidiscip- } \\
\text { linary }\end{array}$ & Textile & Wood & Total \\
\hline 1993 & 9 & 43 & 15 & 30 & 36 & 673 & 12 & 8 & 826 \\
\hline 1994 & 6 & 38 & 23 & 25 & 24 & 692 & 2 & 15 & 825 \\
\hline 1995 & 19 & 55 & 24 & 40 & 32 & 754 & 41 & 5 & 970 \\
\hline 1996 & 12 & 61 & 32 & 36 & 17 & 772 & 48 & 4 & 982 \\
\hline 1997 & 17 & 54 & 43 & 26 & 30 & 922 & 50 & 5 & 1147 \\
\hline 1998 & 11 & 56 & 34 & 49 & 34 & 781 & 53 & 8 & 1026 \\
\hline 1999 & 17 & 81 & 28 & 45 & 65 & 895 & 57 & 8 & 1196 \\
\hline 2000 & 25 & 79 & 48 & 43 & 59 & 874 & 64 & 3 & 1195 \\
\hline 2001 & 25 & 83 & 42 & 94 & 79 & 965 & 81 & 9 & 1378 \\
\hline $\begin{array}{l}\text { Av Ann. } \\
\text { Gr Rate }\end{array}$ & 31.81 & 10.44 & 18.22 & 25.00 & 19.85 & 5.12 & 242.54 & 27.92 & 7.09 \\
\hline
\end{tabular}


has been the fastest growing area in materials science witnessing 267.2 per cent growth during 1993-95 to 1999-2001 followed by composites (120.6 per cent), biomaterials (97 per cent), coating and films (91.5 per cent), materials characterisation and testing (90 per cent), and multidisciplinary areas (29 per cent). In wood research, the country showed decline 28.5 per cent in its publications growth during the same period (Table 3 ).

\subsection{Sub-field-Wise Analysis}

Publications activity of the country in materials science was studied sub-field wise to examine and compare to what extent its publications size in each sub-field under different periods of study is comparable with its overall publications size in materials science. In this, data was computed for measuring publications activity index. It is a relative measure and its average value is taken as one. The value of activity index, if more than one, indicates that the publications activity in the respective sub-fields is above the country average. For value of activity index less than one, it indicates that the publications activity in the respective sub-field is below the country average.

The publications activity in multidisciplinary science, though has been as rising at 29 per cent sexennially, but compared to the publications activity in materials science it has been declining gradually from 1.05 in 1993-95 to 1.02 in 1996-98, and to 0.94 in 1999-2001. The publications activity in wood compared to national average in materials science has also been declining gradually, from 1.57 in $1993-95$ to 0.79 in $1996-98$, and to 0.78 in 1999-2001. In all other subjects, publications activity has been gradually rising.
The same trend is also reflected by the growth rate in publications output in these sub-fields (Table 4).

\subsection{Media of Communications}

Indian scientists published papers in materials science in 108 journals (both Indian and foreign) during 1993-2001. Of these, the top 10 journals accounted for 58.79 per cent papers, top 20 journals for 76.93 per cent, top 30 journals for 85.52 per cent, and top 40 for 90.94 per cent papers of the total output in materials science. It implies that the country output in materials science is highly scattered in nearly 68 journals. The list of top 20 journals publishing India's papers in materials science are given in Table 5.

\subsection{Impact of India's Publications Output in Materials Science}

The average impact factor (IF) per paper for the country output in materials science is not high (0.638) since nearly 91.74 per cent of its output is published in low impact journals (IF=0.001-1.999), and 2.7 per cent output in zero impact journals. Its output appearing in medium IF journals (IF $=2.000-$ 3.999) and high impact journals (IF $=4$ and more) is not very significant (3.57 per cent and 1.58 per cent, respectively). This trend is uniform across all sub-fields in materials science. However, the quality of research output in materials science is showing marginal rise with time. Comparing the publications share of the country in different categories of journals during 1993-95 and 1999-200, it was seen that the country's share in zero impact and low impact journals have declined

Table 3. Publications growth in different subfields in materials science during 1993-2001

\begin{tabular}{|l|c|c|c|c|}
\hline \multirow{2}{*}{ Subject } & \multicolumn{3}{|c|}{ Publications count } & \multirow{2}{*}{$\begin{array}{c}\text { Growth rate } \\
\text { 1993-95 to } \\
\text { 1999-2001 }\end{array}$} \\
\cline { 2 - 4 } & $\mathbf{1 9 9 3 - 9 5}$ & $\mathbf{1 9 9 6 - 9 8}$ & $\mathbf{1 9 9 9 - 0 1}$ & 97.06 \\
\hline Biomaterials & 34 & 40 & 67 & 78.68 \\
\hline Ceramics & 136 & 171 & 243 & 90.32 \\
\hline Characterization \& Testing & 62 & 109 & 118 & 91.58 \\
\hline Coatings \& films & 95 & 111 & 182 & 120.65 \\
\hline Composites & 92 & 81 & 203 & 29.02 \\
\hline Multidisciplinary & 2119 & 2475 & 2734 & \\
\hline
\end{tabular}


Table 4. Publications activity of sub-fields in materials science during 1993-2001

\begin{tabular}{|c|c|c|c|c|}
\hline \multirow{2}{*}{$\begin{array}{l}\text { Per cent share } \\
\text { of total output }\end{array}$} & \multirow[t]{2}{*}{ Subject } & \multicolumn{3}{|c|}{ Activity index } \\
\hline & & 1993-95 & $1996-98$ & 1999-01 \\
\hline 97.06 & Biomaterials & 0.88 & 0.86 & 1.20 \\
\hline 78.68 & Ceramics & 0.90 & 0.94 & 1.12 \\
\hline 90.32 & Characterization \& Testing & 0.78 & 1.14 & 1.03 \\
\hline 91.58 & Coatings \& films & 0.89 & 0.87 & 1.19 \\
\hline 120.65 & Composites & 0.89 & 0.65 & 1.37 \\
\hline 29.02 & Multidisciplinary Science & 1.05 & 1.02 & 0.94 \\
\hline 267.27 & Textile & 0.49 & 1.12 & 1.25 \\
\hline-28.57 & Wood & 1.57 & 0.79 & 0.78 \\
\hline 100 & Overall & 1 & 1 & 1 \\
\hline
\end{tabular}

Table 5. Top 20 journals in materials science preferred by Indian scientists for publishing research papers

\begin{tabular}{|c|l|c|}
\hline S.No. & \multicolumn{1}{|c|}{ Journal title } & $\begin{array}{c}\text { Total } \\
\text { publications } \\
\mathbf{1 9 9 3 - 2 0 0 1}\end{array}$ \\
\hline 1 & Bulletin of Materials Science & 816 \\
\hline 2 & Journal of Materials Science Letters & 587 \\
\hline 3 & Journal of Materials Science & 440 \\
\hline 4 & Materials Chemistry and Physics & 337 \\
\hline 5 & Materials Letters & 312 \\
\hline 6 & Indian Journal of Fibre \& Textile Research & 302 \\
\hline 7 & Thin Solid Films & 275 \\
\hline 8 & Microelectronics and Reliability & 257 \\
\hline 9 & Journal of Magnetism and Magnetic Materials & 232 \\
\hline 10 & Materials Research Bulletin & 224 \\
\hline 11 & $\begin{array}{l}\text { Materials Science and Engineering A-Structural Materials } \\
\text { Properties Microstructure and Processing }\end{array}$ \\
\hline 12 & Microwave and Optical Technology Letters & 222 \\
\hline 13 & Journal of Materials Processing Technology & 201 \\
\hline 14 & $\begin{array}{l}\text { Materials Science and Engineering B-Solid State Materials for } \\
\text { Advanced Technology }\end{array}$ & 200 \\
\hline 15 & Journal of Nuclear Materials & 195 \\
\hline 16 & Wear & 179 \\
\hline 17 & Journal of Materials Research & 156 \\
\hline 18 & Journal of Non-Crystalline Solids & 147 \\
\hline 19 & $\begin{array}{l}\text { Metallurgical and Materials Transactions A-Physical Metallurgy } \\
\text { and Materials Science }\end{array}$ & 144 \\
\hline 20 & Journal of Materials Chemistry & 138 \\
\hline
\end{tabular}

from 2.97 per cent to 2.70 per cent, and from 94.24 per cent to 91.74 per cent, respectively, whereas its share in medium and high impact journals have shown marginal rise from 2.44 per cent to 3.57 per cent and from and 0.34 per cent to 1.98 per cent, respectively. This indicates that the quality of research in materials science has marginally increased over the years (Table 6). On analysing the average IF for papers in different sub-fields of materials science during 1993-2001, it was found that maximum impact (1.03 average impact factor per paper) was observed in case of coatings and films followed by biomaterials (0.98), multidisciplinary materials science $(0.91)$, ceramics (0.90), composites (0.45), wood $(0.33)$, characterisation and testing $(0.30)$, and textiles (0.21). In most of the sub-fields the average impact factor per paper have increased during 1993-95 to 1999-2001. The maximum increase (from 0.70 to 1.15 ) in IF per paper was reported in case of multidisciplinary materials science followed by wood (from 0.18 to 0.44 ), biomaterials (from 0.84 to 
1.08), composites (from 0.39 to 0.49 ), ceramics (from 0.83 to 0.97 ), etc. (Table 7 ).

\subsection{Collaborative Profile in Materials Science}

Of the total 9545 papers reported by India in materials science during 1993-2001, 2910 (30.48 per cent) were through collaborative research. The country showed significant rise in collaborative papers from 346 (13.2 per cent) to 1620 (42.9 per cent) during 1993-1995 to 1999-2001. The rise in collaborative research output (368.2 per cent) was greater than the rise in country's output in materials science research ( 7.09 per cent) during the corresponding period (Table 8 ). Of the total 9545 papers in materials science, 2101 (22 per cent) were through collaborative research at national level and 972 (10.2 per cent) through collaborative research at international level. The rise in collaborative research at national level was higher from 236 to 1152 papers ( 9.0 per cent to 30.56 per cent) than the rise in collaborative research at international level from 132 to 565 papers (4.65 per cent to 14.99 per cent) during $1993-95$ to 1999 2001. The collaboration through bilateral participation was greater (859 papers, 88.37 per cent) then collaboration through multilateral participation (113 papers, 11.62 per cent). However, bilateral research showed decline (from 94.26 per cent to 86.72 per cent) and multilateral research showed rise (from 5.74 per cent to 13.27 per cent) during 1993-1995 to 1999-2001 (Table 9). The collaborative share of research, as seen from the number of publications, was the largest (37.62 per cent) in coatings, followed by composites (34.31 per cent), multidisciplinary materials science (31.45 per cent), biomaterials science (27.66 per cent), etc. The collaborative share at national level was the largest (27.39 per cent) in composites followed by coatings (22.84 per cent), multidisciplinary materials science (22.64 per cent), textiles (20.83 per cent), etc. The collaborative share at international level was the largest in coatings (18.04 per

Table 6. Research output in different IF range during 1993-1995 to 1999-2001

\begin{tabular}{|l|c|c|c|c|c|}
\hline \multirow{2}{*}{ IF Range } & \multicolumn{3}{|c|}{ Total Papers } & \multicolumn{2}{c|}{ Total Papers } \\
\cline { 2 - 6 } & $\mathbf{1 9 9 3 - 9 5}$ & $\mathbf{1 9 9 6 - 9 8}$ & $\mathbf{1 9 9 9 - 0 1}$ & $\begin{array}{c}\text { Per cent } \\
\text { share }\end{array}$ \\
\hline $0.00-0.00$ & 78 & 138 & 42 & 258 & 2.70 \\
\hline $0.01-1.99$ & 2470 & 2879 & 3408 & 8757 & 91.74 \\
\hline $2.00-3.99$ & 64 & 117 & 160 & 341 & 3.57 \\
\hline 4 and more & 9 & 21 & 159 & 189 & 1.98 \\
\hline Total & 2621 & 3155 & 3769 & 9545 & 100 \\
\hline
\end{tabular}

Table 7. Average IF per paper in different subfields of materials science

\begin{tabular}{|c|c|c|c|c|}
\hline Subfields & $1993-95$ & 1996-98 & $1999-2001$ & $1993-2001$ \\
\hline Biom aterials & 0.84 & 0.99 & 1.04 & 0.98 \\
\hline Ceramics & 0.83 & 0.84 & 0.97 & 0.90 \\
\hline Characterisation & 0.31 & 0.27 & 0.32 & 0.30 \\
\hline Coatings & 1.10 & 0.82 & 1.13 & 1.03 \\
\hline Composites & 0.39 & 0.41 & 0.49 & 0.45 \\
\hline Multidisciplinary & 0.70 & 0.81 & 1.15 & 0.91 \\
\hline Textile & 0.24 & 0.16 & 0.24 & 0.21 \\
\hline Wood & 0.18 & 0.45 & 0.44 & 0.33 \\
\hline
\end{tabular}

Table 8. Publications output by nature of collaboration in materials science

\begin{tabular}{|l|c|c|c|c|}
\hline Period & TP & TCP & TNCP & TICP \\
\hline $93-95$ & 2621 & 346 & 236 & 122 \\
\hline $96-98$ & 3155 & 944 & 713 & 285 \\
\hline $99-01$ & 3769 & 1620 & 1152 & 565 \\
\hline $93-01$ & 9545 & 2910 & 2101 & 972 \\
\hline
\end{tabular}

TP=Total Papers; TCP=Total Collaborative Papers; TNCP=Total National Collaborative Papers; TICP=Total International Collaborative Papers 
cent) followed by wood (12.31 per cent), ceramics (10.91 per cent), multidisciplinary materials science (10.53 per cent), etc.

\subsection{Institutional Productivity and Quality}

A total of 933 institutions belonging to academic and mission-oriented research in the country participated in materials research during 1993-2001. Of these, top 83 institutions accounted for 80 per cent research output and the remaining 850 for just 20 per cent research output (Table 10). It implies that the pockets of excellence in materials science research are highly localised.

Of the top 20 institutions, 12 were academic institutions (IISc Bangalore; IIT Kharagpur, Chennai, Mumbai, Kanpur, Delhi; SHIVUK; BANAUV; COLL-IT-VA; ANNAUM; Delhi University, Delhi; and RRL, Thiruvanthapuram) and eight mission-oriented institutions (BARC, IGCAR, DMRL, IACS, CGCRI, NPL, NCL, and CERI).

Table 9. Publications output by nature of collaboration in materials science sub-fields

\begin{tabular}{|l|c|c|c|c|}
\hline Sub-fields & TP & TCP & TNCP & TICP \\
\hline Biomaterials & 141 & 39 & 28 & 13 \\
\hline Ceramics & 550 & 134 & 83 & 60 \\
\hline Characterisation & 289 & 60 & 48 & 13 \\
\hline Coatings & 388 & 146 & 89 & 70 \\
\hline Composites & 376 & 129 & 103 & 33 \\
\hline Multidisciplinary & 7328 & 2305 & 1659 & 772 \\
\hline Textile & 408 & 86 & 85 & 3 \\
\hline Wood & 65 & 11 & 6 & 8 \\
\hline Total & 9545 & 2910 & 2101 & 972 \\
\hline
\end{tabular}

$T P=$ Total papers; $T C P=$ Total collaborative papers; $T N C P=$ Total national collaborative papers; $T I C P=$ Total international collaborative papers

Table 10. Leading institutions in materials science in India during 1993-2001

\begin{tabular}{|l|c|c|c|}
\hline \multirow{2}{*}{ Institution code } & \multicolumn{3}{|c|}{ Papers (1993-2001) } \\
\cline { 2 - 4 } & Total & $\begin{array}{c}\text { Cumulative } \\
\text { per cent }\end{array}$ & $\begin{array}{c}\text { Average } \\
\text { IF/paper }\end{array}$ \\
\hline IIS & 995 & 7.78 & 1.189 \\
\hline IIT, Kharagpur & 695 & 5.44 & 0.781 \\
\hline IITM, Chennai & 495 & 3.87 & 0.648 \\
\hline BARC & 487 & 3.81 & 0.948 \\
\hline IITB, Mumbai & 426 & 3.33 & 0.741 \\
\hline IGCAR & 405 & 3.17 & 0.772 \\
\hline IIT, Kanpur & 357 & 2.79 & 0.79 \\
\hline IITD, New Delhi & 349 & 2.73 & 0.531 \\
\hline DMRL & 298 & 2.33 & 1.176 \\
\hline IACS & 281 & 2.20 & 0.939 \\
\hline CGCRI & 256 & 2.00 & 0.779 \\
\hline NPL & 250 & 1.96 & 0.814 \\
\hline SHIVUK & 230 & 1.80 & 0.733 \\
\hline BANAUV & 227 & 1.78 & 0.991 \\
\hline NCL & 205 & 1.60 & 1.275 \\
\hline COLL-IT-VA & 166 & 1.30 & 0.85 \\
\hline ANNAUM & 162 & 1.27 & 0.679 \\
\hline DELHUD & 161 & 1.26 & 0.682 \\
\hline CERI & 156 & 1.22 & 0.69 \\
\hline RRL-TRIV & 154 & 1.20 & 0.773 \\
\hline
\end{tabular}




\section{CONCLUSION}

As seen from publications data in the Web of Science, materials science research in the country is not stagnant, but growing steadily at about seven per cent per year. Currently, the publications activity is the fastest in composites followed by textiles, biomaterials, coating and films, and ceramics. In wood science, the publications activity is below the country average. The research institutions publish mainly in low impact journals and very little in high impact journals. It is for this reason that the average impact per paper of the country in materials science is low. The collaborative research is growing faster (368.2 per cent) than the country growth in materials science research (7.09 per cent). The bilateral participation in materials science research is greater (88.37 per cent) than collaboration through multilateral participation (11.62 per cent). The pockets of excellence are localised to select few institutions out of 933 institutions, which participated in materials science research during 1993-2001.

\section{REFERENCES}

1. Kochhar, V.B., et al. Materials research in India: A quantitative analysis. In Bibliometrics, scientometrics and informatrics, edited by B.M.Gupta. Segment, New Delhi, 1996. pp. 154-63.

2. Mohan, S., et al. Materials science research and development in India: A scientometric analysis of international collaborative output. DESIDOC Bull. Inf. Technol., 2003, 23(2), 11-23.

\section{Contributor}

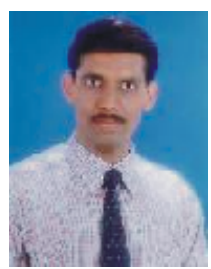

Mr Rajpal Walke did his BSc in 1990. After doing BLiS and MLiS, he did MPhil in Library and Information Science in 2005. His areas of interest are bibliometric analysis, scientomertric analysis, collection development, library management, administration, and application of IT in LIS. He has a number of publications to his credit. Presently, he is working as Technical Officer in National Physical Laboratory. 